\title{
Garrapata en pene
}

\author{
J. Casasola Chamorro, S. Gutiérrez García*, Mํㅗ. Suárez Fernández, R. Guerreiro González, \\ F.J. Gallo Rosanía
}

Servicio de Urología. **Servicio de Ginecología ***Medicina de Familia. Complejo Hospitalario de León. León.

Actas Urol Esp 2005; 29 (6): 618

$\mathrm{L}^{-1}$ os traumatismos de casa animal en genitales Cexternos son infrecuentes a pesar de la accesibilidad de la zona. La picadura por garrapata adquiere importancia como transmisora de enfermedades (Enfermedad de Leyme, borreliosis, tifus, etc...) y por la permanencia del insecto en el lugar de la misma y la dificultad en su extirpación.

El tratamiento implica la extracción completa del insecto y de su órgano succionador, siendo necesaria la cirugía en caso de que esté muerto y medidas físicas como gasolina, aceites, vaselina o

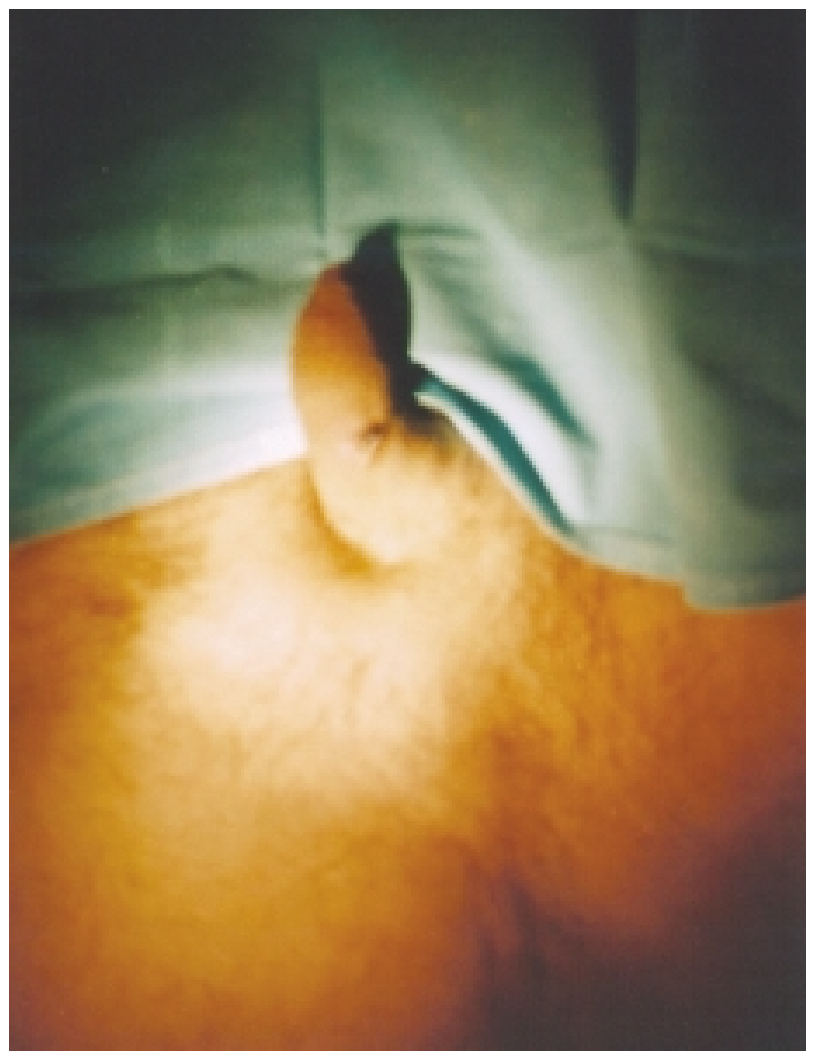

FIGURA 1 la transfixión del mismo con una aguja candente en caso de que permanezca vivo. En el caso de la imagen fue necesaria la extirpación quirúrgica del insecto así como del área de ulceración de la piel adyacente.

Dr. J. Casasola Chamorro

C/ Santo Toribio de Mogrovejo 70, 5ㅇ I 24006 León

e.mail: jcasasola@hleo.sacyl.es

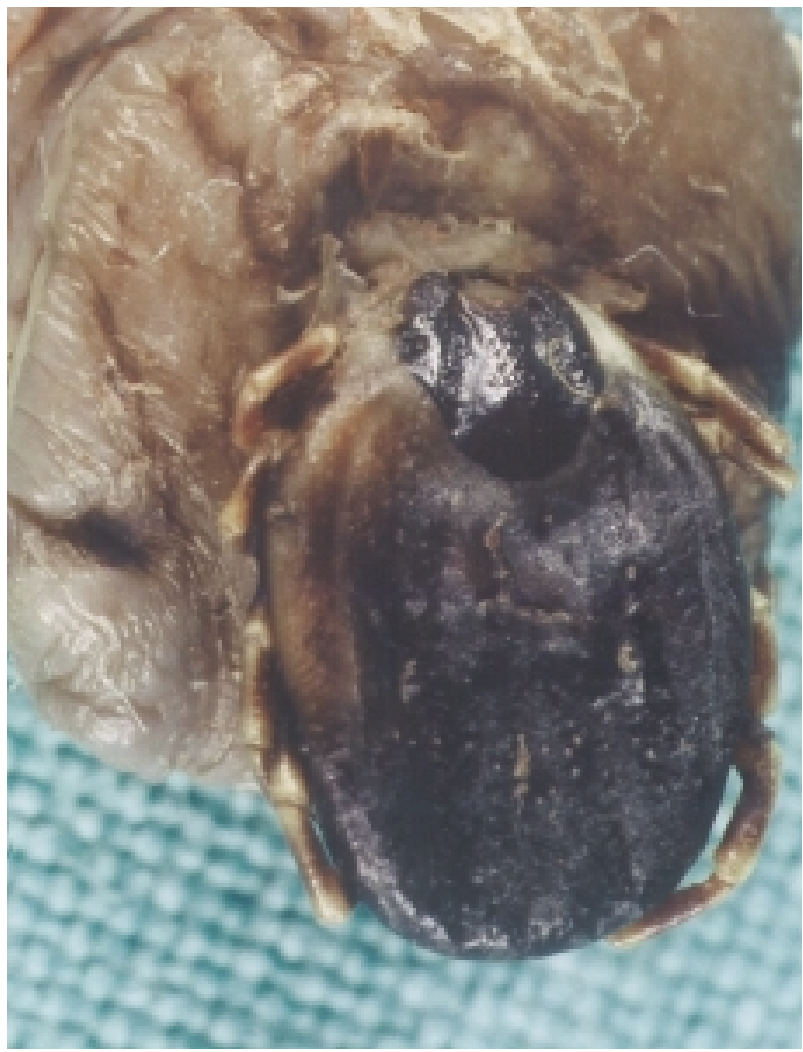

FIGURA 2 